\title{
Scottish Intercollegiate Guidelines Network updates caries guideline
}

SIGN, the Scottish Intercollegiate Guidelines Network recently launched updated guidance on dental interventions to prevent caries in children (SIGN guideline 138).

The guideline replaces SIGN guideline 47 on preventing dental caries in children at high-caries risk and SIGN guideline 83 on prevention and management of dental decay in the pre-school child. The guideline provides recommendations based on current evidence for best practice in dental interventions to prevent caries in children aged 0-18 years carried out by dental care teams within dental practices in Scotland.

The guideline focuses on advice or interventions that are applied at an individual rather than a population level. The full guideline and quick reference guide can be downloaded from the SIGN website www.sign.ac.uk.

A commentary on the guideline will appear in a forthcoming issue of the journal.

Evidence-Based Dentistry (2014) 15, 29. doi: 10.1038/sj.ebd.6400991

\section{CASP updates}

\section{website}

CASP, the Oxford-based Critical Skills Appraisal Programme, which has been involved in developing core evidence-based health care skills since 1993, has launched its new update website www.casp-uk.net.

The website has details about forthcoming workshops and activities, the highly popular CASP checklists, as well as some e-learning modules, so it is well worth a visit.

Evidence-Based Dentistry (2014) 15, 29. doi: $10.1038 /$ sj.ebd.6400992

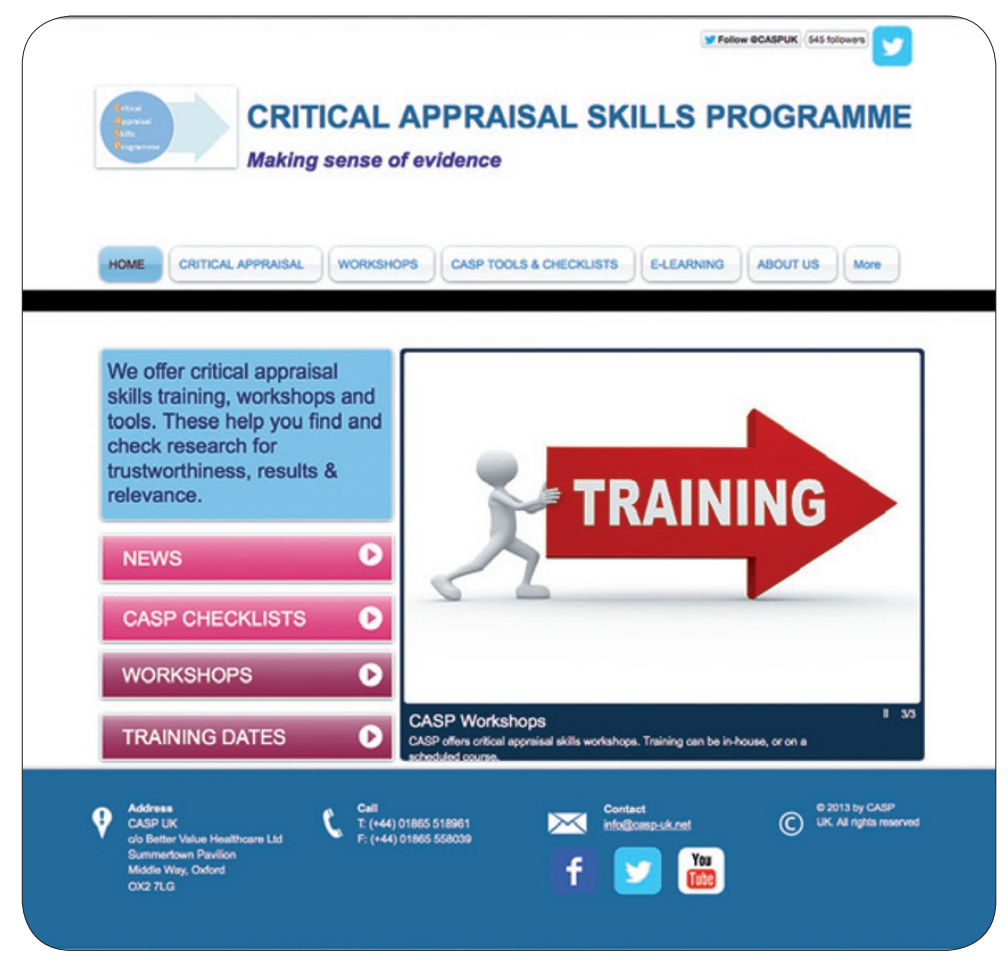

Figure 1. CASP website home page

\section{UK EBD Teachers' Group formed}

A number of those involved in delivering evidence-based dentistry teaching to dental undergraduates in the UK have formed a UK-wide group to share ideas and resources.

At the first online meeting held on March 17th 2014 the group discussed areas of mutual interest.

Amongst these were how to facilitate the transfer of evidence into clinical decision-making, what level of content is appropriate at the undergraduate level and when to teach it and how.

There was enthusiasm among the participants to share curricula, develop online content together and identify strate- gies to help incorporate evidence use in clinical practice.

The group is keen to engage representatives from all UK dental and hygiene-therapy schools. Some colleagues have already responded but were unable to attend this inaugural meeting so a second one is due to be held.

Please get in touch with Nicola Innes (n.p.innes@dundee. ac.uk) or Dominic Hurst (r.d.hurst@qmul.ac.uk) if you lead on EBD at your institution and would like to join.

Evidence-Based Dentistry (2014) 15, 29. doi: 10.1038/sj.ebd.6400993 